\title{
Analysis of risk factors for unplanned reoperation following primary repair of gastrointestinal disorders in neonates
}

\author{
Yu Cui ${ }^{*}{ }^{+}$, Rong Cao ${ }^{\dagger}$, Jia Li and Ling-mei Deng
}

\begin{abstract}
Background: The aim of our study was to identify the factors associated with unplanned reoperations among neonates who had undergone primary repair of gastrointestinal disorders.

Methods: A retrospective chart review was conducted for neonates who underwent primary gastrointestinal surgery between July 2018 and September 2020. The neonates were divided into two cohort, depending on whether they had an unplanned reoperation. The primary outcome was the occurrence of unplanned reoperation. The risk factors that associated the occurrence of unplanned reoperation were examined.

Main results: Two hundred ninety-six neonates fulfilled the eligibility criteria. The incidence of unplanned reoperation was $9.8 \%$. Analyses of all patients with respect of developing unplanned reoperation showed that the length of operative time was an independent risk factor [Odds Ratio 1.02; 95\% confidence interval 1.00, 1.04; $p=$ 0.03]. Patients with unplanned reoperation had a longer postoperative hospital length-of-stay [19.9 \pm 14.7 vs. $44.1 \pm$ 32.1 days; $p<0.01]$.

Conclusion: The current study is the first analysis of risk factors associated with an unplanned reoperation in neonates undergoing primary repair of gastrointestinal disorders. The length of operative time is the only risk factor for an unplanned reoperation, and the unplanned reoperation can directly prolong the postoperative hospital length-of-stay.

Trial registration: This study was registered at http://www.chictr.org.cn/index.aspx with No. ChiCTR2000040260.

Keywords: Intraoperative hypothermia, Unplanned reoperation, Neonates, Gastrointestinal disorders
\end{abstract}

\section{Background}

Surgical intervention is typically an effective procedure in neonates with gastrointestinal disorders, such as congenital anorectal malformation, hypertrophic pyloric stenosis, congenital intestinal atresia, and neonatal necrotizing enterocolitis. It is well understood that compared to children and adults, neonatal patients are at

\footnotetext{
*Correspondence: cuiyu19831001@163.com

${ }^{+}$Yu Cui and Rong Cao contributed equally to this work.

Department of Anesthesiology, The Affiliated Hospital, School of Medicine, UESTC Chengdu Women's \& Children's Central Hospital, No.1617, Riyue Avenue, Qingyang District, Chengdu 610091, P.R. China
}

higher risk in the perioperative period [1]. With the development of remarkable healthcare advances in neonatal surgery, most patients have excellent outcomes after surgical interventions, but some neonates with postoperative complications still require unplanned reoperation.

According to the prior publications, rates of unplanned abdominal reoperation varied from 14 to $38.8 \%$ in neonates with jejunoileal atresia [2-5]. In 2019, Zhu et al. presented that $15(6.0 \%)$ of neonates required reoperation following Ladd's procedure [6]. Meanwhile, they revealed that the incidence of unplanned reoperation

(c) The Author(s). 2021 Open Access This article is licensed under a Creative Commons Attribution 4.0 International License, which permits use, sharing, adaptation, distribution and reproduction in any medium or format, as long as you give appropriate credit to the original author(s) and the source, provide a link to the Creative Commons licence, and indicate if changes were made. The images or other third party material in this article are included in the article's Creative Commons licence, unless indicated otherwise in a credit line to the material. If material is not included in the article's Creative Commons licence and your intended use is not permitted by statutory regulation or exceeds the permitted use, you will need to obtain permission directly from the copyright holder. To view a copy of this licence, visit http://creativecommons.org/licenses/by/4.0/ The Creative Commons Public Domain Dedication waiver (http://creativecommons.org/publicdomain/zero/1.0/) applies to the data made available in this article, unless otherwise stated in a credit line to the data. 
was $17.9 \%$ in neonates with apple-peel atresia following surgical intervention [7]. The indications for unplanned reoperation in neonates with gastrointestinal disorders included surgical site infections, functional obstruction [8], operative adhesive intestinal obstruction and anastomotic obstruction [7].

In other fields, the unplanned reoperation rate had been used as an indicator for evaluating a hospital's ability to provide safe and efficient care [9]. Unplanned reoperations that associated with prolonged length of hospital stay and raised healthcare costs increased medical burden. Moreover, unplanned reoperations decreased patients' satisfaction and strongly associated with surgical and medical complications [10]. Ademuyiwa et al. had clarified that reoperation was a significant determinant of mortality in neonates with intestinal obstruction [11]. However, few studies investigated the risk factors associated with unplanned reoperation following primary repair of gastrointestinal disorders in neonates.

We, therefore, reviewed our experience to identify the factors associated with unplanned reoperations among neonates who had undergone primary repair of gastrointestinal disorders. The aim of our study was to provide evidence on optimizing clinical decision-making and improving outcomes in those patients.

\section{Methods}

This was a single center, descriptive, retrospective study, which was conducted at a large tertiary hospital $(>300$ beds in NICU) in western region of China. Ethic approval was obtained from the Institutional Review Board (IRB) in Chengdu Women's and Children's Central Hospital. This study was registered at http://www.chictr.org. cn/index.aspx with No. ChiCTR2000040260 on November 27,2020 . The informed consent was waived because of anonymous patients' data by the IRB of Chengdu Women's and Children's Central Hospital.

\section{Patient selection}

All anesthesia and perioperative warming methods were performed in accordance with the guidelines in our institution. Neonates (aged $0 \sim 28$ days) who received primary gastrointestinal surgery between July 2018 and September 2020 were enrolled in our study. Patients without sufficient data for analysis were excluded. Patients were divided into two cohorts, depending on whether they had an unplanned reoperation. An unplanned reoperation was defined as an unexpected return to the operating room within 30 days due to complications related to the original surgical intervention, regardless of whether the event occurred during a hospitalization or a readmission. The primary outcome was the occurrence of unplanned reoperation. Then, the risk factors that associated the occurrence of unplanned reoperation were identified.

\section{Data collection}

The data was extracted from the institutional database, combining with medical chart review. Demographic variables were collected, i.e., age at surgery, weight at surgery, birth weight, gender, gestational days, ASA status, preoperative hemoglobin, and preoperative transfusion. Intraoperative outcomes were also recorded, including type of surgeries, surgical services, the length of operative time, duration of anesthesia time, mean body temperature, the incidence of hypothermia, the length of intraoperative hypothermia, estimated blood loss, blood transfusion, fluid infusion, postoperative hemoglobin, and intraoperative urinary output. Postoperative variables included postoperative ventilator dependence hours, postoperative hemoglobin, acute renal failure (AKI), postoperative hospital length-of-stay (PLOS) and hospital mortality. Duration of anesthesia time was defined as the time from anesthesia induction to discharge from the operating room at the initial operation. The length of operative time was calculated from skin incision to the end of suture. The diagnostic criteria of AKI were based on the modified KDIGO definition of neonatal AKI [12]. Hospital mortality data was obtained according to the protocol of our previous study [13]. Notably, total length of actual PLOS was calculated from surgical date to discharge date. If the patient is readmitted, PLOS need to be accumulated. The variables were double-checked by medical chart review.

\section{Definition of inadvertent intraoperative hypothermia}

In our institution, intraoperative temperature was routinely monitored through esophagus rather than the rectum. According to the definition of the National guideline in UK [14], intraoperative hypothermia was defined as body temperature $<36.0^{\circ} \mathrm{C}$. The patient's core temperature was continuously monitored and recorded automatically at $5 \mathrm{~min}$ interval until discharging from the operating room. When $<36.0^{\circ} \mathrm{C}$ was recorded on the electronic anesthesia record, this patient was considered to have hypothermia [14]. The length of intraoperative hypothermia was calculated from the beginning of hypothermia to the beginning of normothermia. If hypothermia occurred repeatedly, the length of hypothermia needed to be added up. All temperature data were extracted at the primary surgery.

\section{Statistical analysis}

Continuous variables were presented as the mean \pm standard deviation [SD] or median and interquartile range [IQR] (25-75\%) if nonnormally distributed. The student $t$ test was used to compare normally distribute data, 
otherwise the Mann Whitney U-test was used to compare two groups. The categorical variables were expressed as numbers and percentages. The Pearson's chi-squared test or Fisher exact test was used as appropriate. Statistical analyses progressed from univariate to multivariate analyses (Tables 1 and 2). Univariate logistic regression was performed to identify associations with unplanned reoperation. Significant variables in univariate analysis were added to the multivariate regression model (Table 3). Clinically significant variables and those with $p$-value on univariate regression of $<0.20$, were subsequently included in a multivariate regression model [15]. All analyses were conducted with $\mathrm{R}$ studio 3.5.2. $P<0.05$ was statistically significant, and all tests were two-sided.

\section{Results}

\section{Unplanned reoperation rates}

Overall, a total of 401 neonates undergoing gastrointestinal surgical interventions were identified between July 2018 and September 2020. Of those, 105 neonates were excluded because of missing data. Finally, 296 neonates were included in the analysis, 29 (9.8\%) of them underwent an unplanned reoperation within 30 days after the initial surgery (Fig. 1).

\section{Demographic and clinical characteristics}

Demographic and clinical characteristics for the two cohorts were presented in Table 1. More male patients $(177,59.8 \%)$ than female patients underwent gastrointestinal surgery during the neonatal period, but the difference in gender distribution between the two cohorts was not significant. There was no statistical difference between the two cohorts in terms of age, birth weight, weight at surgery, gestational days, ASA status, the value of preoperative hemoglobin or preoperative blood transfusion (Table 1). Among clinical variables, patients undergoing anoplasty were less likely to require unplanned reoperation (Non-reoperation: $59,22.1 \%$ vs. Reoperation: $1,3.4 \% ; p=$ $0.03)$, whereas patients undergoing enterectomy were more likely to require unplanned reoperation (Nonreoperation: $168,62.9 \%$ vs. Reoperation: $26,89.7 \%$; $p<0.01)$. In addition, compared to patients without reoperation, patients who underwent an unplanned reoperation had a higher incidence of intraoperative hypothermia (Non-reoperation: 215, 80.5\% vs. Reoperation: $28,96.6 \% ; p<0.01$ ), and a longer duration of hypothermia (Non-reoperation: $87.4 \pm 82.5 \mathrm{~min}$ vs. Reoperation: $124.4 \pm 83.0 \mathrm{~min} ; p<0.01$ ). Furthermore, both the length of primary operative time (Non-reoperation: $91.3 \pm 43.5 \mathrm{~min}$ vs. Reoperation: $119.3 \pm$ $58.1 \mathrm{~min} ; p<0.01)$ and total length of hospital stay (Non-reoperation: $19.9 \pm 14.7$ days vs. Reoperation: $44.1 \pm 32.1$ days; $p<0.01$ ) were longer in patients with unplanned reoperation than patients without reoperation (Table 2).

Table 1 Demographics and characteristics of eligible neonates

\begin{tabular}{|c|c|c|c|c|}
\hline \multirow[b]{3}{*}{ Variables } & \multicolumn{3}{|l|}{ Patients, No. (\%) } & \multirow{3}{*}{$p$ value } \\
\hline & \multirow[b]{2}{*}{ Total $(N=296)$} & \multicolumn{2}{|c|}{ Unplanned Reoperation } & \\
\hline & & No $(N=267)$ & Yes $(N=29)$ & \\
\hline Gender, male, n (\%) & $177(59.8)$ & $161(60.3)$ & $16(55.2)$ & $0.74^{\mathrm{a}}$ \\
\hline Birth weight (kg), median (IQR) & $2.9(2.2,3.3)$ & $2.9(2.2,3.3)$ & $2.8(2.0,3.1)$ & $0.30^{b}$ \\
\hline Very low birth weight $(<1.5 \mathrm{~kg})$ & $24(8.1)$ & $20(7.5)$ & $4(13.8)$ & $0.27^{c}$ \\
\hline Weight at surgery (kg), median (IQR) & $2.9(2.2,3.3)$ & $2.9(2.2,3.3)$ & $2.9(2.4,3.2)$ & $0.85^{b}$ \\
\hline Gestational age (days), median (IQR) & $266.0(245.0,274.0)$ & $266.0(245.0,274.0)$ & $258.0(244.0,274.0)$ & $0.49^{b}$ \\
\hline Gestational weeks (<37), n (\%) & $127(10.0)$ & $112(8.2)$ & $15(17.2)$ & $0.42^{\mathrm{a}}$ \\
\hline Gestational weeks (37 য), n (\%) & $169(90.0)$ & $155(91.8)$ & $14(82.8)$ & \\
\hline Age at the surgery (days), median (IQR) & $6.0(4.0,12.0)$ & $6.0(4.0,11.0)$ & $6.0(4.0,16.0)$ & $0.25^{b}$ \\
\hline ASA & & & & $0.91^{c}$ \\
\hline । & $1(0.3)$ & $1(0.4)$ & $0(0.0)$ & \\
\hline$\|$ & $83(28.0)$ & $76(28.5)$ & $7(24.1)$ & \\
\hline III & $191(64.5)$ & $171(64.0)$ & $20(69.0)$ & \\
\hline IV & $21(7.1)$ & $18(7.1)$ & $2(6.9)$ & \\
\hline Preoperative hemoglobin $(\mathrm{g} / \mathrm{dl})$, mean $\pm \mathrm{SD}$ & $147.2 \pm 45.3$ & $147.5 \pm 45.8$ & $144.0 \pm 41.2$ & $0.90^{b}$ \\
\hline Preoperative blood transfusion, $\mathrm{n}(\%)$ & $46(15.5)$ & $38(14.2)$ & $8(27.6)$ & $0.11^{\mathrm{a}}$ \\
\hline
\end{tabular}

Note: $n$ Sample, SD Standard deviation, IQR Interquartile Range

adenotes a $p$ value based on a Pearson' chi-squared test

${ }^{b}$ denotes a $p$ value based on a Mann-Whitney U-test

c denotes a $p$ value based on a fisher exact test 
Table 2 Intraoperative and postoperative data

\begin{tabular}{|c|c|c|c|c|}
\hline \multirow[t]{2}{*}{ Variables } & \multirow[b]{2}{*}{ Total $(N=296)$} & \multicolumn{2}{|c|}{ Unplanned reoperation } & \multirow[t]{2}{*}{$p$ value } \\
\hline & & No $(N=267)$ & Yes $(N=29)$ & \\
\hline Type of surgeries & & & & $0.10^{a}$ \\
\hline Elective, n (\%) & $85(28.7)$ & $81(30.3)$ & $4(13.8)$ & \\
\hline Emergency, n (\%) & $211(71.3)$ & $186(69.7)$ & $25(86.2)$ & \\
\hline \multicolumn{5}{|l|}{ Surgical services, n (\%) } \\
\hline Anoplasty & $60(20.3)$ & $59(22.1)$ & $1(3.4)$ & $0.03^{* a}$ \\
\hline Appendectomy & $1(0.3)$ & $1(0.4)$ & $0(0.0)$ & $1.00^{\mathrm{a}}$ \\
\hline Diaphragmatic hernia repair & $4(1.4)$ & $4(1.5)$ & $0(0.0)$ & $1.00^{\mathrm{a}}$ \\
\hline Enterectomy & $194(65.5)$ & $168(62.9)$ & $26(89.7)$ & $<0.01 * \mathrm{~b}$ \\
\hline Gastric perforation repair & $9(3.0)$ & $8(3.0)$ & $1(3.4)$ & $1.00^{\mathrm{a}}$ \\
\hline Hernia repair & $2(0.7)$ & $2(0.7)$ & $0(0.0)$ & $1.00^{\mathrm{a}}$ \\
\hline Intestinal malrotation repair & $3(1.0)$ & $3(1.1)$ & $0(0.0)$ & $1.00^{\mathrm{a}}$ \\
\hline Intestinal Volvulus reduction & $4(1.4)$ & $3(1.1)$ & $1(3.4)$ & $0.34^{a}$ \\
\hline Ovariocysrectomy & $2(0.7)$ & $2(0.7)$ & $0(0.0)$ & $1.00^{\mathrm{a}}$ \\
\hline Pyloric myotomy & $5(1.7)$ & $5(1.9)$ & $0(0.0)$ & $1.00^{\mathrm{a}}$ \\
\hline Umbilical bulge repair & $12(4.1)$ & $12(4.5)$ & $0(0.0)$ & $0.62^{a}$ \\
\hline Operative time (min), mean \pm SD & $94.0 \pm 45.6$ & $91.3 \pm 43.5$ & $119.3 \pm 58.1$ & $<0.01^{* c}$ \\
\hline Operation time > 120 min, n (\%) & $63(20.8)$ & $49(18.4)$ & $14(48.3)$ & $<0.01 * \mathrm{~b}$ \\
\hline Duration of anesthesia (min), mean \pm SD & $164.6 \pm 61.9$ & $162.1 \pm 60.7$ & $187.3 \pm 65.9$ & $<0.01^{* c}$ \\
\hline Mean intraoperative temperature $\left({ }^{\circ} \mathrm{C}\right)$, mean $\pm \mathrm{SD}$ & $35.8 \pm 0.8$ & $35.8 \pm 0.8$ & $35.6 \pm 0.7$ & $0.11^{c}$ \\
\hline$\geq 36$ and $<37.5\left({ }^{\circ} \mathrm{C}\right), \mathrm{n}(\%)$ & $134(45.3)$ & $125(46.8)$ & $9(31.0)$ & $0.15^{b}$ \\
\hline$\geq 35$ and $<36.0\left({ }^{\circ} \mathrm{C}\right), \mathrm{n}(\%)$ & $86(29.1)$ & $77(28.8)$ & $9(31.0)$ & $0.86^{\mathrm{b}}$ \\
\hline$<35.0\left({ }^{\circ} \mathrm{C}\right), \mathrm{n}(\%)$ & $76(25.7)$ & $65(25.7)$ & $11(37.9)$ & $0.17^{b}$ \\
\hline Duration of hypothermia (min), mean \pm SD & $91.1 \pm 83.4$ & $87.4 \pm 82.5$ & $124.4 \pm 83.0$ & $<0.01 * c$ \\
\hline The incidence of hypothermia, $\mathrm{n}(\%)$ & $243(82.1)$ & $215(80.5)$ & $28(96.6)$ & $0.04^{* b}$ \\
\hline Intraoperative blood loss (ml), mean \pm SD & $4.4 \pm 4.0$ & $4.2 \pm 3.8$ & $5.7 \pm 5.5$ & $0.08^{c}$ \\
\hline Intraoperative transfusion $(\mathrm{ml})$, mean \pm SD & $6.7 \pm 12.0$ & $6.3 \pm 11.2$ & $10.5 \pm 19.2$ & $0.99^{c}$ \\
\hline Intraoperative total fluid infusion $(\mathrm{ml} / \mathrm{kg} / \mathrm{h})$, mean \pm SD & $1.3 \pm 0.6$ & $1.3 \pm 0.6$ & $1.2 \pm 0.5$ & $0.38^{c}$ \\
\hline Intraoperative urine output (ml/kg/h), mean \pm SD & $1.9 \pm 1.5$ & $2.0 \pm 1.5$ & $1.7 \pm 1.2$ & $0.15^{c}$ \\
\hline Postoperative hemoglobin $(\mathrm{g} / \mathrm{dl})$, mean $\pm \mathrm{SD}$ & $127.3 \pm 36.1$ & $127.7 \pm 36.0$ & $123.7 \pm 37.1$ & $0.40^{c}$ \\
\hline Postoperative ventilation (hours), median (IQR) & $35.1(16.4,68.7)$ & $33.9(16.4,67.9)$ & $42.3(17.3,81.9)$ & $0.35^{c}$ \\
\hline Ventilation dependence> 48 h, n (\%) & $107(36.1)$ & $93(34.8)$ & $14(48.3)$ & $0.22^{b}$ \\
\hline Postoperative AKI, n (\%) & $27(9.1)$ & $25(9.4)$ & $2(6.9)$ & $0.92^{a}$ \\
\hline Postoperative hospital length-of-stay (days), mean \pm SD & $22.2 \pm 17.6$ & $19.9 \pm 14.7$ & $44.1 \pm 32.1$ & $<0.01 * c$ \\
\hline Mortality, n (\%) & $33(11.1)$ & $29(10.9)$ & $4(13.8)$ & $0.63^{a}$ \\
\hline
\end{tabular}

Note: $n$ Sample, SD Standard deviation, IQR Interquartile Range, AKI Acute kidney injury, ${ }^{*} P<0.05$

a denotes a $p$ value based on a fisher exact test

${ }^{b}$ denotes a $p$ value based on a Pearson' chi-squared test

'denotes a $p$ value based on a Mann-Whitney U-test

\section{Risk factor analysis}

The following 13 variables (type of surgeries, anoplasty, enterectomy, other surgical services, intraoperative mean body temperature, duration of hypothermia, the incidence of intraoperative hypothermia, the length of operative time, duration of anesthesia, intraoperative blood loss, and duration of postoperative ventilator dependence) were identified as risk factors for reoperation in the univariate analysis (Table 3). Multivariable logistic regression analysis (Table 3 ), including factors with $P<0.2$ on univariate analysis, identified that the length of primary operative time (OR, 1.02; 95\%CI, 1.00-1.04) was the independent risk factors for unplanned reoperation. 
Table 3 Univariate and Multivariate analysis of risk factors associated with unplanned reoperation in neonates after gastrointestinal procedures

\begin{tabular}{|c|c|c|c|c|}
\hline \multirow[t]{2}{*}{ Independent Variable } & \multicolumn{2}{|c|}{ Univariate analysis } & \multicolumn{2}{|l|}{ Multivariate analysis } \\
\hline & OR $(95 \% \mathrm{Cl})$ & $P$ value & Adjusted OR $(95 \% \mathrm{Cl})$ & $P$ value \\
\hline Weight at surgery (kg) & $0.94(0.55,1.6)$ & 0.83 & & \\
\hline Birth weight < $1.5(\mathrm{~kg})$ & $1.98(0.63,6.24)$ & 0.24 & & \\
\hline Gestational weeks (<37 vs. $\geq 37$ ) & $1.48(0.69,3.2)$ & 0.32 & & \\
\hline Type of surgeries (Elective vs. Emergency) & $2.72(0.92,8.07)$ & 0.07 & $0.33(0.10,1.09)$ & 0.07 \\
\hline \multicolumn{5}{|l|}{ Surgical services, n (\%) } \\
\hline Anoplasty & $0.13(0.02,0.94)$ & $0.04^{*}$ & $0.04(0.00,1.15)$ & 0.06 \\
\hline Enterectomy & $5.11(1.51,17.31)$ & $<0.01 *$ & $0.20(0.01,2.92)$ & 0.24 \\
\hline others & $0.22(0.03,1.68)$ & 0.15 & $0.05(0.00,1.47)$ & 0.08 \\
\hline \multicolumn{5}{|l|}{ Mean intraoperative temperature, $\mathrm{n}(\%)$} \\
\hline$\geq 36$ and $<37.5\left({ }^{\circ} \mathrm{C}\right)$ & $0.51(0.22,1.16)$ & 0.11 & $0.74(0.17,3.22)$ & 0.69 \\
\hline$\geq 35$ and $<36.0\left({ }^{\circ} \mathrm{C}\right)$ & $1.11(0.48,2.55)$ & 0.81 & & \\
\hline$<35.0\left({ }^{\circ} \mathrm{C}\right)$ & $1.9(0.85,4.23)$ & 0.12 & $1.81(0.52,6.24)$ & 0.35 \\
\hline Duration of hypothermia (min) & $1.01(1.00,1.01)$ & $0.01 *$ & $1.00(0.99,1.01)$ & 0.82 \\
\hline The incidence of hypothermia, n (\%) & $6.77(0.90,50.91)$ & 0.06 & $4.61(0.42,51.13)$ & 0.21 \\
\hline Operative time (min) & $1.01(1.01,1.02)$ & $<0.01 *$ & $1.02(1.00,1.04)$ & $0.03^{*}$ \\
\hline Preoperative transfusion, n (\%) & $2.3(0.95,5.56)$ & 0.07 & $1.44(0.52,4.00)$ & 0.97 \\
\hline Duration of anesthesia (min) & $1.00(0.99,1.01)$ & 0.08 & $0.99(0.98,1.01)$ & 0.48 \\
\hline Preoperative hemoglobin (g/dl) & $1.00(0.99,1.01)$ & 0.79 & & \\
\hline Postoperative hemoglobin (g/dl) & $1.00(0.98,1.01)$ & 0.52 & & \\
\hline Intraoperative blood loss (mL) & $1.04(0.98,1.1)$ & 0.17 & $0.99(0.91,1.05)$ & 0.60 \\
\hline Postoperative ventilation (hours) & $1.00(1.00,1.00)$ & 0.10 & $1.00(1.00,1.00)$ & 0.75 \\
\hline
\end{tabular}

Note: Clinically significant variables and those with $p$-value on univariate regression of $<0.20$ were subsequently included in the multivariate regression model; $95 \%$ Confidence Intervals $(95 \% \mathrm{Cl}),{ }^{*} P<0.05$ is statistically significant

\section{Discussion}

In our study, we used the electrical database from Chengdu Women's and Children's Central hospital to identify risk factors for an unplanned reoperation following primary repair of gastrointestinal disorders in neonates. We found that the length of primary operative time was the independent risk factors for unplanned reoperation and patients with unplanned reoperation had a longer PLOS.

\section{The importance of identification of risk factors}

To our knowledge, serious postoperative complications, such as bleeding, intestinal obstruction, leakage, and infection, can lead to an unplanned reoperation. Unplanned reoperations are harmful to the patients due to repeated exposure to anesthetics and surgical pressure, especially in neonates with immature liver and kidney function. Furthermore, unplanned reoperation increases the family's economic and psychological burden. Additionally, Ademuyiwa et al. has proved that reoperation was a significant determinant of mortality [11]. Therefore, identification of risk factors in advance is essential to improve the quality of perioperative management and provide the evidence for medical decision-making.

\section{The incidence of unplanned reoperation in neonates}

In neonates, surgical intervention is required because of congenital malformation or acquired condition on gastrointestinal tract. Obviously, compared with adults or older children, neonates are at a higher risk due to the requirement for more delicate surgical techniques and poorer tolerance of surgical and anesthetic pressure. The incidence of unplanned reoperation varies greatly in different types of surgery. A retrospective study evaluated the unplanned reoperation rate following plastic surgery in pediatric patients and showed an overall rate of $0.8 \%(137 / 18106)$ within 30 days after surgery [10]. However, 23.3\% (10/43) patients required unplanned reoperation after primary repair for jejunoileal atresia [8]. Theoretically, a more complex primary procedures is associated with an increased likelihood of a patient experiencing unplanned reoperation, as were the younger age. Unfortunately, there were few studies about the incidence of unplanned reoperation after gastrointestinal surgery in neonates. Studies in neonates were focused 


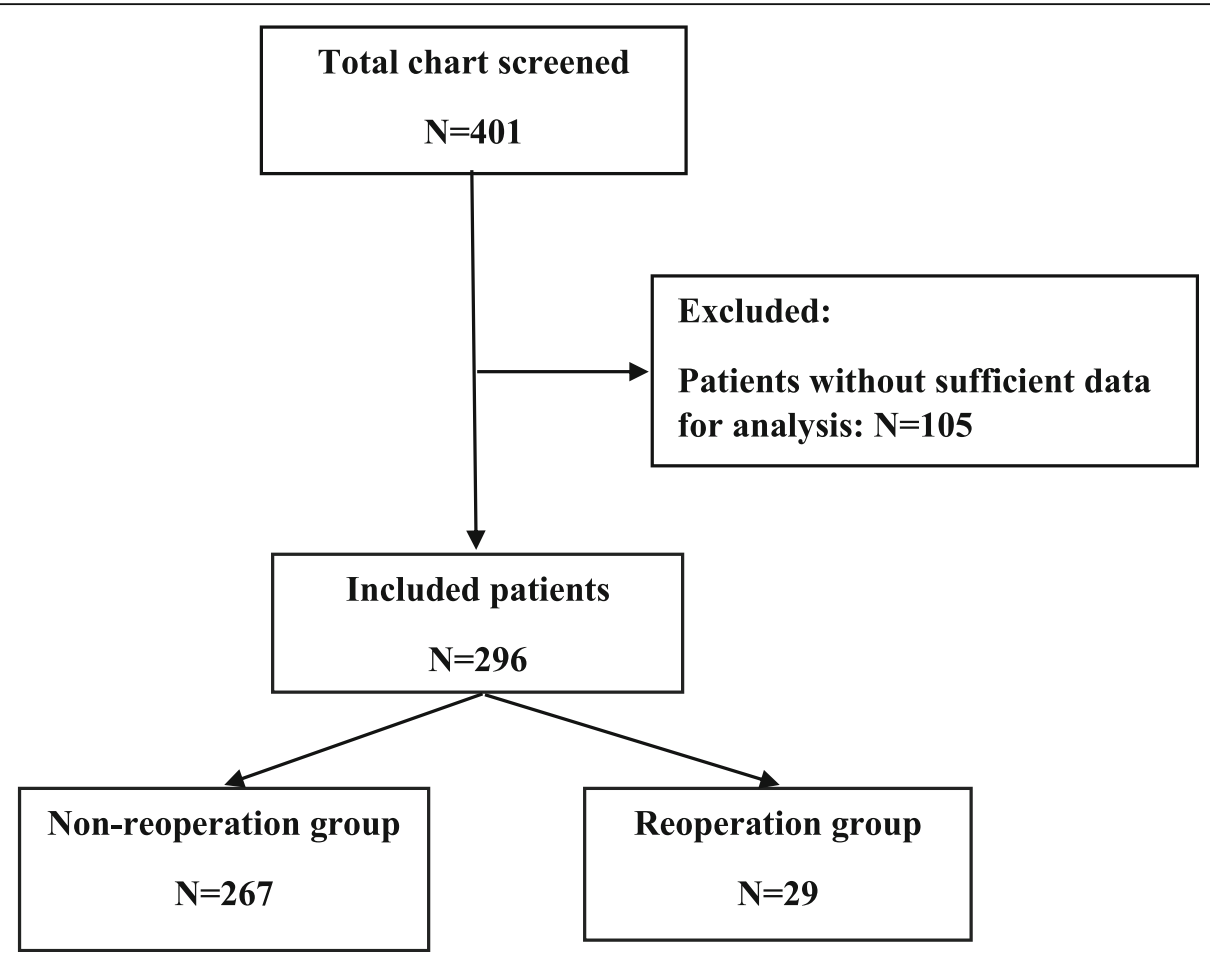

Fig. 1 Study patient flow diagram

on relatively small series, most of which focus on a single procedure. Our study summarized a total of 296 newborns who underwent gastrointestinal surgery, including 11 types of surgical procedures, of which 254 (85.8\%) underwent anoplasty or enterectomy. Only 1 patient $(1 / 60,1.7 \%)$ who underwent anoplasty experienced an unplanned reoperation, whereas $26(26 / 194,13.4 \%)$ patients who underwent enterectomy received reoperation. Totally, 9.8\% neonates suffered unplanned reoperation, which was in line with previous reports.

\section{Risk factors associated with unplanned reoperation}

In theory, demographic characteristics, surgical services, and intraoperative features, as well as postoperative complications were all related to unplanned reoperation. In univariate analysis, anoplasty (OR $0.13 ; p=0.04$ ), enterectomy (OR $5.11 ; p<0.01$ ), duration of intraoperative hypothermia (OR 1.01; $p=0.01$ ), and the length of operative time (OR $1.01 ; p<0.01)$ were significantly associated with unplanned reoperation. However, our multivariate regression analyses identified that the only factor associated with unplanned reoperation was prolonged operative time, which was consistent with previous research [16]. In plastic surgery, an association between increasing operative time and incidence of unplanned reoperation had been confirmed [10]. And Sangal et al. had revealed that a greater total operation time was associated with an unplanned reoperation in major operations of the head and neck [16]. These results could be interpreted as a more complex surgical procedure would be more likely to require unplanned reoperation. The prolonged operative time could be considered as a sign of procedure complexity. Reoperation resulted in a longer PLOS (Non-reoperation: 19.9 \pm 14.7 days vs. Reoperation: $44.1 \pm 32.1$ days, $p<0.001)$. None of the remaining variables were significantly associated with unplanned reoperation in multivariate model, though some had been identified as risk factors in existing literature. A previous report which reviewed 9 nineyear experience in managing neonates with jejunoileal atresia presented that prematurity and low birth weight were associated with functional obstruction leading to reoperation [8]. However, this conclusion was drawn from a relatively small sample size, including only 43 patients undergoing enterectomy, which reduced its credibility. With the development of neonatal care and the improvement of surgical skills in recent years, the premature neonates with low birth weight could be well treated, which might decrease the requirement of surgical intervention.

Although neither duration of hypothermia nor incidence of hypothermia were identified as risk factors in multivariant analysis, their potential effects should be taken seriously. Compared to patients without reoperation, patients with reoperation had a longer duration of hypothermia and higher incidence of hypothermia 
during initial surgical period. Intraoperative hypothermia might increase the risk of surgical site infection [17] and even death [18]. The authors randomly assigned the patients to either normothermic or hypothermic group. They reported that surgical site infections were 19\% of patients in hypothermic group and $6 \%$ of patients in the normothermic group $(P=0.009)$, and the length of hospitalization was extended by 2.6 days in the hypothermia group $(P=0.01)$ [17]. We also demonstrated that PLOS was longer in patients with reoperation than those without reoperation. Those results could be interpreted as delayed healing because of wound infections. Additionally, a meta-analysis that included 48 studies had presented that most neonates with surgical site infection had gastrointestinal and/or colorectal surgery [19]. Surgical site infection was associated with increased risk of unplanned reoperation in major head and neck surgery [16]. Thus, we speculated that gastrointestinal surgery was associated with a high risk of unplanned secondary surgery. But in China, due to the disharmonious relationship between medical workers and patients, surgical site infection might not be recorded objectively. Therefore, limited in data collection restricted further analysis in current study.

\section{Limitations}

The limitations in our study were as follows. First, although this cohort study was conducted in medical center which was the largest neonatal surgery center in western region of China, the sample size was still insufficient for further subgroup analysis. Second, the variation of surgeons' expertise could not be well controlled, as the evaluation system of surgeons had not been fully established in our center. Next, gastrointestinal surgeries might be a consequence of patent ductus arteriosus (PDA) $[20,21]$. The stealing blood flow from aorta to pulmonary arteries via PDA might exceed the physiological compensatory mechanisms, with a consequence of decreasing organ perfusion. The available literature has proved that prolonged ductal patency was associated with higher mortality rates and several adverse outcomes, including impaired renal function and necrotizing enterocolitis (NEC) [21]. However, in our institutional database, the diagnoses, especially in emergency surgical patients, were not well-documented. Sometimes, only the diagnosis of surgical indications was recorded. Thus, it was difficult to consider PDA as a variable in the analysis, but it was an important factor that should be discussed. In the future, we will communicate with neonatologist and surgeons to improve the patient's diagnosis record. Last, the number of variables assessed was very limited, especially variables related to baseline clinical condition and intraoperative course. There was a high risk of unexplored confounding factors. Yet, we believed that length of operation remained a good marker of a complex procedure due to either surgical or anesthesiologic factors.

\section{Conclusions}

The current study is the first analysis of risk factors associated with an unplanned reoperation in neonates undergoing primary repair of gastrointestinal disorders. The length of operative time is the only risk factor for an unplanned reoperation, and the unplanned reoperation can directly prolong the PLOS. We wish this study can help to identify high-risk patients and improve clinical decision-making.

\section{Abbreviations \\ OR: Odds Ratio; IRB: Institutional Review Board; Cl: Confidence interval; PLOS: Postoperative hospital length-of-stay; AKI: Acute renal failure; \\ IQR: Interquartile range}

\section{Acknowledgements}

Not applicable.

\section{Authors' contributions}

C.Y., L.J. and D.L.M. performed the data collection. C.Y. and C.R. conducted the statistical analysis. C.Y. wrote the first draft of manuscript. C.R. did the proof reading. All authors read and approved the final manuscript.

\section{Funding}

This work was supported by grants from Health and family planning Commission of Sichuan Province (No. 16PJ072).

\section{Availability of data and materials}

The datasets generated and analyzed during the current study are not publicly available because patients' name and admission number are included in the datasets but are available from the corresponding author on reasonable request.

\section{Declarations}

Ethics approval and consent to participate

After obtaining Institutional Review Board (IRB) approval [No. 2020 (14)], we retrieved patient data from the electrical record system at Chengdu Women's and Children's Central Hospital.

\section{Consent for publication}

Not applicable.

\section{Competing interests}

The authors declare no competing interests.

Received: 26 November 2020 Accepted: 13 April 2021

Published online: 23 April 2021

\footnotetext{
References

1. Section on Anesthesiology and Pain Medicine, Polaner DM, Houck CS. American Academy of Pediatrics: critical elements for the pediatric perioperative anesthesia environment. Pediatrics. 2015;136(6):1200-5.

2. Kumaran N, Shankar KP, Lloyd DA, Losty PD. Trends in the management and outcome of jejunoileal atresia. Eur J Pediatr Surg. 2002;12:163-7.

3. Calisti A, Olivieri C, Coletta R, Briganti V, Oriolo L, Giannino G. Jejunoileal atresia: factors affecting the outcome and long-term sequelae. J Clin Neonatol. 2012;1:38-41.

4. Federici S, Sabatino MD, Domenichelli V, Straziuso S. Worst prognosis in the complex jejunoileal atresia: is it real? Eur J Pediatric Surg Rep. 2015;3:7-11.

5. Peng $\mathrm{Y}-\mathrm{F}$, Zheng $\mathrm{H}-\mathrm{Q}$, Zhang $\mathrm{H}$, He Q-M, Wang Z, Zhong W, et al. Comparison of outcomes following three surgical techniques for patients with severe jejunoileal atresia. Gastroenterol Rep (Oxf). 2019;7(6):444-8. https://doi.org/10.1093/gastro/goz026.
} 
6. Zhu H, Zheng S, Alganabi M, Peng X, Dong K, Pierro A, et al. Reoperation after Ladd's procedure in the neonatal period. Pediatr Surg Int. 2019;35:11720. https://doi.org/10.1007/s00383-018-4382-6.

7. Zhu H, Gao R, Alganabi M, Dong K, Ganji N, Xiao X, et al. Long-term surgical outcomes of apple-peel atresia. J Pediatr Surg. 2019;54:2503-8. https://doi. org/10.1016/j.jpedsurg.2019.08.045.

8. Yeung F, Tam YH, Wong YS, Tsui SY, Wong HY, Pang KKY, et al. Early Reoperations after Primary Repair of Jejunoileal Atresia in Newborns. J Neonatal Surg. 2016;5:42. https://doi.org/10.21699/jns.v5i4.444.

9. Molina ES, Schildmacher C, Doods J, Freistühler M, Hellwig SJ, Stummer W, et al. The rise of quality indicators in neurosurgery: 30-day unplanned reoperation rate evaluated in 3760 patients-a single-center experience. Acta Neurochir (Wien). 2020;162(1):147-56. https://doi.org/10.1007/s00701-01904146-2.

10. Jubbal KT, Zavlin D, Buchanan EP, Hollier LH Jr. Analysis of risk factors associated with unplanned reoperations following pediatric plastic surgery. J Plast Reconstr Aesthet Surg. 2017;70:1440-6. https://doi.org/10.1016/j. bjps.2017.05.008,

11. Ademuyiwa AO, Sowande OA, ljaduola TK, Adejuyigbe O. Determinants of mortality in neonatal intestinal obstruction in lle Ife, Nigeria. Afr J Paediatr Surg. 2009;6:11-3. https://doi.org/10.4103/0189-6725.48568.

12. Jetton JG, Askenazi DJ. Acute kidney injury in the neonate. Clin Perinatol. 2014;41:487-502. https://doi.org/10.1016/j.clp.2014.05.001.

13. Yu C, Yu W, Cao R, Li G, Deng L, Li J. The low fresh gas flow anesthesia and hypothermia in neonates undergoing digestive surgeries: a retrospective before-after study. BMC Anesthesiol. 2020;20:223.

14. National Institute for Health and Care Excellence. Inadvertent perioperative hypothermia: the management of inadvertent perioperative hypothermia in adult [CG65] [Internet]. London: National Institute of Health and Care Excellence [UK]; 2016. http://www.nice.org.uk/guidance/cg65

15. Lyu HG, Sharma G, Brovman EY, Ejiofor J, Urman RD, Gold JS, et al. Unplanned reoperation after hepatectomy: an analysis of risk factors and outcomes. HPB (Oxford). 2018;20:591-6. https://doi.org/10.1016/j.hpb.201 7.12.006.

16. Sangal NR, Nishimori K, Zhao E, Siddiqui SH, Baredes S, Park RCW. Understanding Risk factors associated with unplanned reoperation in major head and neck surgery. JAMA Otolaryngol Head Neck Surg. 2018:144:1044-51.

17. Kurz A, Sessler DI, Lenhardt R. Perioperative normothermia to reduce the incidence of surgical-wound infection and shorten hospitalization. Study of wound infection and temperature group. N Engl J Med. 1996;334:1209-15.

18. Akers JL, Dupnick AC, Hillman EL, Bauer AG, Kinker LM, Hagedorn WA. Inadvertent perioperative hypothermia risks and postoperative complications: a retrospective study. AORN J. 2019;109:741-7. https://doi. org/10.1002/aorn.12696.

19. Catania VD, Boscarelli A, Lauriti G, Morini F, Zani A. Risk Factors for Surgical Site Infection in Neonates: A Systematic Review of the Literature and MetaAnalysis. Front Pediatr. 2019;7:101. https://doi.org/10.3389/fped.2019.00101.

20. El Manouni El Hassani S, Niemarkt HJ, Derikx JPM, et al. Predictive factors for surgical treatment in preterm neonates with necrotizing enterocolitis: a multicenter case-control study. Eur J Pediatr. 2020. https://doi.org/10.1007/ s00431-020-03892-1.

21. Martini S, Aceti A, Galletti S, Beghetti I, Faldella G, Corvaglia L. To feed or not to feed: a critical overview of enteral feeding management and gastrointestinal complications in preterm neonates with a patent Ductus Arteriosus. Nutrients. 2019:12:83.

\section{Publisher's Note}

Springer Nature remains neutral with regard to jurisdictional claims in published maps and institutional affiliations.

Ready to submit your research? Choose BMC and benefit from:

- fast, convenient online submission

- thorough peer review by experienced researchers in your field

- rapid publication on acceptance

- support for research data, including large and complex data types

- gold Open Access which fosters wider collaboration and increased citations

- maximum visibility for your research: over $100 \mathrm{M}$ website views per year

At BMC, research is always in progress.

Learn more biomedcentral.com/submissions 